\title{
BEZPIECZEŃSTWO BUDOWLI PIĘTRZĄCYCH - STUDIUM PORÓWNAWCZE DOKUMENTÓW NORMATYWNYCH
}

\author{
Zbigniew Kledyński ${ }^{\bowtie}$, Łukasz Krysiak \\ Wydział Instalacji Budowlanych, Hydrotechniki i Inżynierii Środowiska, Politechnika Warszawska, Warszawa
}

\begin{abstract}
STRESZCZENIE
Krajowe przepisy prawne, obowiązujące w obszarze projektowania budowli hydrotechnicznych, są niekompletne i pozostawiają wiele niejasności. W niniejszym artykule przedstawiono to na przykładzie zasad sprawdzania nośności zapór, gdzie napotyka się na odwołania do nieaktualnych norm, niewyjaśnionych pojęć, a także rozmaitych metod, często przestarzałych wobec współcześnie wprowadzanych norm europejskich. Dla porównania przytoczono niektóre zapisy niemieckiej normy DIN 19700-11:2004-07, która dokonuje systematycznej klasyfikacji warunków pracy budowli, przypadków obciążeń, wymienia zestawy oddziaływań wchodzące w skład kombinacji oraz opierając się na metodzie całkowitego współczynnika bezpieczeństwa, określa wymagania w każdej sytuacji obliczeniowej. Jednocześnie dokument ten otwiera drogę do wprowadzenia metody częściowych współczynników bezpieczeństwa na podstawie doświadczeń projektantów.
\end{abstract}

Słowa kluczowe: budowle hydrotechniczne, metody projektowania, niezawodność zapór

\section{WPROWADZENIE}

Rozporządzenie Ministra Środowiska z dnia 20 kwietnia 2007 r. w sprawie warunków technicznych, jakim powinny odpowiadać budowle hydrotechniczne i ich usytuowanie (Dz.U. 86 z 2007 poz. 579) różni się od poprzedniej wersji z 1997 roku (Dz.U. $1997 \mathrm{nr} 21$ poz. 111), ale wprowadzone zmiany nie są konsekwentne co do jednolitości metod zapewniania stateczności i nośności - można zaryzykować tezę, że tę rozmaitość podejść powiększają. Oznacza to, że obowiązujące przepisy podstawowe dla projektowania i utrzymania odpowiedzialnych budowli piętrzących oddają stan wiedzy i doświadczeń sprzed lat i nie uwzględniają znaczących zmian, jakie zaszły w zakresie normalizacji, w tym wprowadzenia Eurokodów. Nawet jak na tak konserwatywną dziedzinę techniki, jaką jest budownictwo wodne, okres adaptacji jest stanowczo zbyt długi. Warto więc przyjrzeć się polskim przepisom techniczno-budowlanym w zakresie budowli piętrzących i chociażby je porównać ze stosowanymi za granicą.

Przedmiotem artykułu jest studium porównawcze przywołanego na początku rozporządzenia (Dz.U. 2007 nr 86 poz. 579) i niemieckiej normy DIN 19700-11:2004-07. Stauanlagen. Teil 11: Talsperren, wyłącznie w zakresie zasad kształtowania bezpieczeństwa konstrukcyjnego zapór. Ze względu na głównego adresata artykułu polskie przepisy zostały omówione skrótowo, a więcej miejsca poświęcono przybliżeniu normy niemieckiej, być może mniej znanej w polskim środowisku hydrotechnicznym. 


\section{PRZEPISY POLSKIE}

Rozporządzenie (Dz.U. 2007 nr 86 poz. 579) nie określa jasno, czy obliczenia statyczne i wytrzymałościowe powinny być wykonywane metodą stanów granicznych, czy np. naprężeń dopuszczalnych. W $§ 29$ wskazuje się na metody określone w polskich normach, ale ich wykaz pokazany w załączniku nr 1 nie jest aktualny ani też wyczerpujący to zagadnienie.

W konsekwencji w tekście rozporządzenia pojawiają się swoiste „hybrydy”, np. w § 34 ust. 1 podano formułę „dla sprawdzania warunków stateczności według I stanu granicznego nośności budowli hydrotechnicznej...” (z wyjątkiem skarp i zboczy tych budowli), w której oddziaływania stabilizujące i destabilizujące występują w swoich wartościach obliczeniowych (a więc odpowiadają wartościom charakterystycznym przemnożonym przez odpowiednie częściowe współczynniki bezpieczeństwa), ale dodatkowo oddziaływania destabilizujące są mnożone przez większy od jedności współczynnik konsekwencji zniszczenia budowli (zależny od klasy jej ważności), a oddziaływania stabilizujące mnożone przez mniejszy od jedności współczynnik korekcyjny, ustalany według bliżej niezidentyfikowanych polskich norm. W ten sposób połączono współczynniki częściowe bezpieczeństwa, właściwe dla metody stanów granicznych, ze współczynnikiem konsekwencji zniszczenia, który ma charakter całkowitego współczynnika bezpieczeństwa (przyjmuje on wartości od 1,0 do 1,2, zależnie od klasy ważności budowli i rodzaju układu obciążeń - załącznik nr 3 do Rozporządzenia (Dz.U. 2007 nr 86 poz. 579)).

W przypadku sprawdzania gradientów filtracji (§ 37) i stateczności skarp oraz zboczy (§ 39) wykorzystuje się z kolei wartości charakterystyczne oddziaływań, a bezpieczeństwo ma zagwarantować współczynnik pewności. Współczynnik ten ma charakter całkowitego współczynnika bezpieczeństwa, ale bez zrozumiałych powodów oderwano go od klasy ważności obiektu, a związano z dokładnością metody obliczeniowej. W efekcie sprawdzanie stateczności skarp i zboczy odbywa się metodą nieomal klasyczną.

Zagadnienie oddziaływań sejsmicznych potraktowano bardzo ogólnie i pobieżnie, zwłaszcza względem współczesnych zaleceń i praktyki (Świdziński i Korzec, 2015).

Na uwagę zasługuje stosowanie dwóch układów obciążeń: podstawowego i wyjątkowego. Zdefiniowano je w $\S 3$ ust. 14 i ust. 15 rozporządzenia (Dz.U. $2007 \mathrm{nr} 86$ poz. 579). I tak, podstawowy układ obciążeń budowli piętrzącej to „obciążenia występujące przy pełnej sprawności jej urządzeń i poziomie piętrzenia przy wezbraniu obliczeniowym o przepływie $Q_{m}$ ", a wyjątkowy układ obciążeń to obciążenia mniej korzystne niż w układzie podstawowym, w tym:

- przy przepływie kontrolnym $\left(Q_{k}\right)$ lub najwyższym obliczeniowym stanie wody $(H)$,

- dynamiczne, powstałe w wyniku oddziaływań sejsmicznych lub parasejsmicznych,

- spowodowane awarią budowli hydrotechnicznej, jej elementów lub niesprawnością drenażu,

- wywołane nierównomiernym odkształceniem powierzchni na terenach górniczych, na obszarach występowania zjawisk krasowych oraz zapadania gruntów lessowych,

- dynamiczne, wywołane ruchem pojazdów, kry i innych przedmiotów pływających,

- spowodowane huraganowym wiatrem,

- spowodowane nagłym obniżeniem poziomu piętrzenia.

Znamienne jest niekonsekwentne połączenie w pojęciu układu obciążeń zarówno ich rodzajów, jak i warunków pracy budowli, przy jednoczesnym braku zasad łączenia obciążeń w kombinacje prowadzące do ustalenia miarodajnych do wymiarowania. W budowaniu tych kombinacji swój udział mają także odpowiednio zdefiniowane warunki pracy obiektu, zależne od zjawisk hydrologicznych i stanu technicznego budowli, zwłaszcza urządzeń upustowych.

W dokumencie pojawiają się także pojęcia „wyjątkowe warunki pracy budowli” ( $\$ 49$ ust. $3, \S 53$ ust. 2 , $\S 59$ ust. 3 i $\S 68$ ) oraz „kombinacja podstawowa i wyjątkowa obciążeń” (§ 34 ust. 3). Pojęć tych nie wyjaśnio- 
Kledyński, Z. i Krysiak, Ł. (2017). Bezpieczeństwo budowli piętrzących - studium porównawcze dokumentów normatywnych. Acta Sci. Pol. Architectura, 16 (3), 89-96. doi: 10.22630/ASPA.2017.16.3.09.

no w tzw. słowniczku, tj. § 3 rozporządzenia (Dz.U. $2007 \mathrm{nr} 86$ poz. 579). Wydaje się to niedopatrzeniem, ale sprawa może być poważniejsza.

\section{PRZEPISY NIEMIECKIE}

\section{Oddziaływania na konstrukcje}

Zagadnienia bezpieczeństwa hydrotechnicznych konstrukcji piętrzących zostały ujęte w rozdziale 7 normy DIN 19700-11:2004-07. Obiekty piętrzące. Część 11: Zapory wodne. W normie operuje się pojęciami z zakresu niezawodności, takimi jak: nośność, użytkowalność i trwałość. W celu sprawdzenia bezpieczeństwa budowli piętrzących i związanego z nimi podłoża wykorzystuje się całkowite współczynniki bezpieczeństwa. Jednocześnie dopuszcza się stosowanie współczynników częściowych, zalecając, aby analizy prowadzić według obu podejść i gromadzić w ten sposób doświadczenia niezbędne do szerszego stosowania w przyszłości metod wykorzystujących częściowe współczynniki bezpieczeństwa.

W takim przypadku odpowiednie obliczenia prowadzone z wykorzystaniem częściowych współczynników bezpieczeństwa powinny zagwarantować równoważny poziom bezpieczeństwa. Przy wyprowadzaniu wartości obliczeniowych oddziaływań w stanie granicznym nośności należy przyjąć ciśnienie statyczne i dynamiczne wody w każdym przypadku obciążeń oraz w każdej sytuacji obliczeniowej jako niezależne oddziaływania stałe. Wysokości piętrzenia miarodajne dla ciśnienia statycznego oraz dynamicznego wody są reprezentacją wartości charakterystycznych tych oddziaływań i mogą być zawsze powiązane z częściowym współczynnikiem bezpieczeństwa równym 1,0 , a ciężar wody może być ogólnie przyjęty jako równy $10,0 \mathrm{kN} \cdot \mathrm{m}^{-3}$.

Oddziaływania na konstrukcję dzieli się na bezpośrednie oraz pośrednie (odkształcenia wymuszone) i grupuje się je ze względu na czas ich trwania oraz częstość występowania:

- grupa 1: oddziaływania stałe oraz często nawracające,

- grupa 2: oddziaływania rzadko występujące oraz ograniczone w czasie,

- grupa 3: oddziaływania wyjątkowe.

W obliczeniach rozpatruje się trzy przypadki obciążeń (LF), będące kombinacjami obciążeń z grup od 1 do 3:

- przypadki obciążeń 1 (kombinacje częste): wszystkie miarodajne oddziaływania grupy 1 ,

- przypadki obciążeń 2 (kombinacje rzadkie): wszystkie miarodajne oddziaływania grupy 1 oraz po jednym oddziaływaniu grupy 2 ,

- przypadki obciążeń 3 (kombinacje wyjątkowe): wszystkie miarodajne oddziaływania grupy 1 oraz po jednym oddziaływaniu grupy 3 .

Zależnie od doboru obciążenia z grup 2 i 3 generowane są zestawy oddziaływań (obciążeń) - tabele 2 i 3 , z których należy wyprowadzić zestawy miarodajne dla sprawdzenia nośności.

Nośność elementów należy sprawdzać w trzech rodzajach warunków pracy budowli:

- warunki pracy A (prawdopodobne): dla pewnych lub powszechnie uznawanych wartości parametrów (unormowanych bądź określonych na podstawie eksperymentów i doświadczenia w sposób pewny) oraz przy w pełni funkcjonującym wyposażeniu,

- warunki pracy B (mało prawdopodobne): dla niekorzystnych wartości parametrów wewnątrz stwierdzonego przedziału ufności lub przy ograniczonej sprawności istotnych elementów wyposażenia budowli,

- warunki pracy C (możliwe w wyjątkowych sytuacjach): dla niekorzystnych wartości parametrów bliskich granicznym lub przy całkowitej awarii istotnych elementów wyposażenia budowli.

W rezultacie kombinacji warunków pracy budowli oraz przypadków obliczeniowych (LF) powstają tzw. sytuacje obliczeniowe (BS) ujęte w tabeli 1. 
Tabela 1. Sytuacje obliczeniowe (BS) od I do III

Table 1. Design situations (BS) I to III

\begin{tabular}{cccc}
\hline \multirow{2}{*}{$\begin{array}{c}\text { Przypadki obciążeń (LF) } \\
\text { Loading conditions (LF) }\end{array}$} & \multicolumn{3}{c}{$\begin{array}{c}\text { Sytuacje obliczeniowe (BS) w warunkach pracy } \\
\text { Design situations (BS) in operating conditions }\end{array}$} \\
\cline { 2 - 4 } & A & B & C \\
\hline 1 & BS I (trwała - persistent) & BS II & - \\
2 & BS II (przejściowa - transient) & BS III & - \\
\hline
\end{tabular}

\section{Zapory ziemne}

Oddziaływania właściwe dla zapór ziemnych i przynależne grupom od 1 do 3 wraz z przypadkami obciążeń pokazano w tabeli 2 .

Tabela 2. Przypadki obciążeń zapór ziemnych

Table 2. Loading conditions of earth dams

Oddziaływania

Actions

Przypadki obciążeń (LF) - Kombinacje obciążeń

Loading conditions (LF) - Combinations of actions

123

\begin{tabular}{|c|c|c|c|c|c|c|c|c|c|}
\hline & & 1.1 & $1.2^{\mathrm{a}}$ & 2.1 & 2.2 & 2.3 & $2.4^{\mathrm{c}}$ & 3.1 & 3.2 \\
\hline & ciężar własny - dead load & $X$ & $\mathrm{X}$ & $X$ & $\mathrm{X}$ & $X$ & $X$ & $X$ & $X$ \\
\hline Grupa 1 & obciążenie komunikacyjne i użytkowe - live load & $\mathrm{X}$ & $\mathrm{X}$ & $\mathrm{X}$ & $\mathrm{X}$ & $\mathrm{X}$ & $\mathrm{X}$ & $X$ & $X$ \\
\hline Group 1 & $\begin{array}{l}\text { parcie statyczne i dynamiczne wody przy poziomie } \\
\text { piętrzenia } Z_{v}^{\text {e }} \\
\text { static pressure and flow force of water at water level } Z_{\mathrm{v}}^{e}\end{array}$ & $X$ & - & - & - & $X$ & $X^{d}$ & - & $\mathrm{X}^{\mathrm{d}}$ \\
\hline
\end{tabular}

parcie statyczne i dynamiczne wody przy maksymalnym

poziomie piętrzenia $1\left(\mathrm{Z}_{\mathrm{H} 1}\right)^{\mathrm{f}}$

static pressure and flow force of water at maximum water

level $1\left(\mathrm{Z}_{\mathrm{H} 1}\right)^{\mathrm{f}}$

Grupa 2 najszybsze możliwe obniżenie zwierciadła wody

Group 2 fastest possible lowering of water level

niezamierzone warunki użytkowania i obciążenia

unintended operating and loading conditions

eksploatacyjne trzęsienie ziemi ${ }^{\mathrm{g}}$ - operating basis earthquake $\mathrm{g}^{\mathrm{g}}$

parcie statyczne i dynamiczne wody przy maksymalnym

Grupa 3 poziomie piętrzenia $2\left(\mathrm{Z}_{\mathrm{H} 2}\right)$, o ile $\mathrm{Z}_{\mathrm{H} 2}>\mathrm{Z}_{\mathrm{H} 1}{ }^{\mathrm{f}}$

static pressure and flow force of water at maximum water

level $2\left(\mathrm{Z}_{\mathrm{H} 2}\right)$, as long as $\mathrm{Z}_{\mathrm{H} 2}>\mathrm{Z}_{\mathrm{H} 1}{ }^{\mathrm{f}}$

obliczeniowe trzęsienie ziemi ${ }^{\text {h }}$ - design basis earthquake ${ }^{\text {h }}$

a Warunki budowy oraz okres konsolidacji aż do końca piętrzenia próbnego, także stan „pusty zbiornik”.

Conditions during construction and consolidation of soil until first impounding, also "empty reservoir" condition.

${ }^{\mathrm{b}}$ Dla poziomu piętrzenia $Z_{\mathrm{V}}$ oraz powyżej. - Water level $Z_{\mathrm{V}}$ or higher.

${ }^{c}$ Przypadek obciążeń tylko do sprawdzenia użytkowalności. - This loading condition only apllies to serviceability verification.

${ }^{d}$ Można przyjąć parcie statyczne oraz dynamiczne odpowiadające normalnemu poziomowi piętrzenia $Z_{\mathrm{S}}$.

Static pressure and flow force of water related to standard operating water level $Z_{\mathrm{S}}$ can be applied.

${ }^{\text {e }}$ Poziom piętrzenia $Z_{\mathrm{v}}$ równy rzędnej korony przelewu lub górnej krawędzi urządzeń upustowych.

Water level $Z_{\mathrm{v}}$ is equal to the elevation of the spillway crest or of the spillway gates' upper edge.

${ }^{\mathrm{f}}$ Poziomy piętrzenia $Z_{\mathrm{H} 1}$ i $Z_{\mathrm{H} 2}$ to maksymalne poziomy piętrzenia występujące w czasie wezbrań o przepływach $\mathrm{BHQ}_{1}$ oraz $\mathrm{BHQ}_{2}(\mathrm{DIN}$ 19700-11:2004-07).

Water levels $\mathrm{Z}_{\mathrm{H} 1}$ and $\mathrm{Z}_{\mathrm{H} 2}$ are maximum water levels associated with flood flows $\mathrm{BHQ}_{1}$ and $\mathrm{BHQ}_{2}(\mathrm{DIN}$ 19700-11:2004-07).

${ }^{\mathrm{g}} \mathrm{Za}$ eksploatacyjne trzęsienie ziemi uznaje się trzęsienie o prawdopodobieństwie przekroczenia $\mathrm{w}$ ciągu roku wynoszącym $2 \times 10^{-3}$ ( $T=500$ lat) dla zapór klasy 1 lub $10^{-2}(T=100$ lat) dla zapór klasy 2.

Operating basis earthquake is an earthquake with yearly exceeding probability of $2 \times 10^{-3}$ ( $T=500$ years) for class 1 dams or $10^{-2}$ ( $T=100$ years) for class 2 dams.

${ }^{\text {h }}$ Za obliczeniowe trzęsienie ziemi uznaje się trzęsienie o prawdopodobieństwie przekroczenia $\mathrm{w}$ ciągu roku wynoszącym $4 \times 10^{-4}$ ( $T=2500$ lat) dla zapór klasy 1 oraz $10^{-3}(T=1000$ lat) dla zapór klasy 2 .

Design basis earthquake is an earthquake with yearly exceeding probability of $4 \times 10^{-4}\left(T=2500\right.$ years) for class 1 dams or $10^{-3}(T=1000$ years) for class 2 dams. 
Kledyński, Z. i Krysiak, Ł. (2017). Bezpieczeństwo budowli piętrzących - studium porównawcze dokumentów normatywnych. Acta Sci. Pol. Architectura, 16 (3), 89-96. doi: 10.22630/ASPA.2017.16.3.09.

Nośność korpusu zapory uznaje się za zapewnioną, kiedy wykaże się obliczeniowo: możliwość przejęcia naprężeń stycznych w powierzchni kontaktu korpusu z podłożem, odporność na wyparcie gruntu spod korpusu, a także przesunięcie zapory lub innych elementów budowli w powierzchni kontaktu z podłożem lub w powierzchni poślizgu w gruncie poniżej (na drodze analizy równowagi sił w powierzchni poślizgu).

W przypadku zapór ziemnych należy zapewnić zachowanie następujących całkowitych współczynników bezpieczeństwa $(\gamma)$ :

- sytuacja obliczeniowa BS I: $\gamma=1,3$,

- sytuacja obliczeniowa BS II: $\gamma=1,2$,

- sytuacja obliczeniowa BS III: $\gamma=1,1$.

W przypadku znaczącego udziału kohezji w utrzymaniu nośności zapory należy zwiększyć wymaganą wartość całkowitego współczynnika bezpieczeństwa o naddatek do 0,1 .

Przy rozpatrywanym na potrzeby analizy ryzyka maksymalnym poziomie piętrzenia $\left(\mathrm{Z}_{\mathrm{H} 1}\right)$ większym niż $\mathrm{Z}_{\mathrm{H} 2}$ bądź, $\mathrm{w}$ razie potrzeby, przy piętrzeniu równym rzędnej korony zapory $\left(\mathrm{Z}_{\mathrm{K}}\right)$ należy utrzymać współczynnik całkowity bezpieczeństwa nie niższy niż $\gamma=1,0$. Jeżeli w wyniku przewidzianych w normie rozważań poziom $\mathrm{Z}_{\mathrm{H} 2}$ odpowiada poziomowi rzędnej korony zapory $\left(\mathrm{Z}_{\mathrm{K}}\right)$, to jako miarodajne należy przyjąć wartości całkowitego współczynnika bezpieczeństwa, jak dla sytuacji obliczeniowej BS III.

\section{Zapory betonowe i murowe}

Oddziaływania właściwe dla zapór betonowych i murowych przynależne grupom od 1 do 3 wraz z przypadkami obciążeń pokazano w tabeli 3 .

Tabela 3. Przypadki obciążeń dla zapór betonowych i murowych

Table 3. Loading conditions of masonry and concrete dams

\begin{tabular}{|c|c|c|c|c|c|c|c|c|c|c|}
\hline \multirow{3}{*}{\multicolumn{2}{|c|}{$\begin{array}{l}\text { Oddziaływania } \\
\text { Actions }\end{array}$}} & \multicolumn{9}{|c|}{$\begin{array}{l}\text { Przypadki obciążeń (LF) - kombinacje obciążeń } \\
\text { Loading conditions (LF) - combinations of actions }\end{array}$} \\
\hline & & \multicolumn{2}{|c|}{1} & \multicolumn{4}{|c|}{2} & \multicolumn{3}{|c|}{3} \\
\hline & & 1.1 & $1.2^{\mathrm{a}}$ & 2.1 & 2.2 & 2.3 & $2.4^{\mathrm{b}}$ & 3.1 & 3.2 & 3.3 \\
\hline \multirow{6}{*}{$\begin{array}{l}\text { Grupa } 1 \\
\text { Group } 1\end{array}$} & ciężar własny - dead load & $\mathrm{X}$ & $\mathrm{X}$ & $\mathrm{X}$ & $\mathrm{X}$ & $\mathrm{X}$ & $\mathrm{X}$ & $\mathrm{X}$ & $\mathrm{X}$ & $\mathrm{X}$ \\
\hline & obciążenie komunikacyjne i użytkowe - live load & $\mathrm{X}$ & $\mathrm{X}$ & $\mathrm{X}$ & $\mathrm{X}$ & $\mathrm{X}$ & $\mathrm{X}$ & $\mathrm{X}$ & $\mathrm{X}$ & $\mathrm{X}$ \\
\hline & $\begin{array}{l}\text { parcie statyczne i dynamiczne wody przy poziomie piętrze- } \\
\text { nia } Z_{V}{ }^{d} \\
\text { static pressure and flow force of water at water level } Z_{V}{ }^{d}\end{array}$ & $\mathrm{X}$ & - & - & $\mathrm{X}^{\mathrm{c}}$ & $\mathrm{X}$ & $X^{c}$ & - & $\mathrm{X}$ & $\mathrm{X}^{\mathrm{c}}$ \\
\hline & parcie gruntu - earth pressure & $\mathrm{X}$ & $\mathrm{X}$ & $\mathrm{X}$ & $\mathrm{X}$ & $\mathrm{X}$ & $\mathrm{X}$ & $\mathrm{X}$ & $\mathrm{X}$ & $\mathrm{X}$ \\
\hline & $\begin{array}{l}\text { długotrwałe oddziaływania temperaturowe } \\
\text { long-term thermal effects }\end{array}$ & $\mathrm{X}$ & $\mathrm{X}$ & $\mathrm{X}$ & $\mathrm{X}$ & $\mathrm{X}$ & $\mathrm{X}$ & $\mathrm{X}$ & - & $\mathrm{X}$ \\
\hline & skurcz i pełzanie betonu - shrinkage and creep of concrete & $\mathrm{X}$ & $\mathrm{X}$ & $\mathrm{X}$ & $\mathrm{X}$ & $\mathrm{X}$ & $\mathrm{X}$ & $\mathrm{X}$ & $\mathrm{X}$ & $\mathrm{X}$ \\
\hline \multirow{4}{*}{$\begin{array}{l}\text { Grupa } 2 \\
\text { Group } 2\end{array}$} & $\begin{array}{l}\text { parcie statyczne i dynamiczne wody przy maksymalnym } \\
\text { poziomie piętrzenia } 1\left(\mathrm{Z}_{\mathrm{H} 1}\right)^{\mathrm{e}} \\
\text { static pressure and flow force of water at maximum water } \\
\text { level } 1\left(\mathrm{Z}_{\mathrm{H} 1}\right)^{\mathrm{e}}\end{array}$ & - & - & $\mathrm{X}$ & - & - & - & - & - & - \\
\hline & $\begin{array}{l}\text { parcie lodu oraz wiatru } \\
\text { ice pressure and wind load }\end{array}$ & - & - & - & $X$ & - & - & - & - & - \\
\hline & $\begin{array}{l}\text { niezamierzone warunki użytkowania i obciążenia } \\
\text { unintended operating and loading conditions }\end{array}$ & - & - & - & - & $X$ & - & - & - & - \\
\hline & $\begin{array}{l}\text { eksploatacyjne trzęsienie ziemi }{ }^{\mathrm{f}} \\
\text { operating basis earthquake }^{\mathrm{f}}\end{array}$ & - & - & - & - & - & $X$ & - & - & - \\
\hline
\end{tabular}


Kledyński, Z. i Krysiak, Ł. (2017). Bezpieczeństwo budowli piętrzących - studium porównawcze dokumentów normatywnych. Acta Sci. Pol. Architectura, 16 (3), 89-96. doi: 10.22630/ASPA.2017.16.3.09.

Tabela 3 - cd.

Table 3 - cont

\begin{tabular}{|c|c|c|c|c|c|c|c|c|c|c|}
\hline \multirow{3}{*}{\multicolumn{2}{|c|}{$\begin{array}{l}\text { Oddziaływania } \\
\text { Actions }\end{array}$}} & \multicolumn{9}{|c|}{$\begin{array}{l}\text { Przypadki obciążeń (LF) - kombinacje obciążeń } \\
\text { Loading conditions (LF) - combinations of actions }\end{array}$} \\
\hline & & \multicolumn{2}{|c|}{1} & \multicolumn{4}{|c|}{2} & \multicolumn{3}{|c|}{3} \\
\hline & & 1.1 & $1.2^{\mathrm{a}}$ & 2.1 & 2.2 & 2.3 & $2.4^{\mathrm{b}}$ & 3.1 & 3.2 & 3.3 \\
\hline \multirow{3}{*}{$\begin{array}{l}\text { Grupa } 3 \\
\text { Group } 3\end{array}$} & $\begin{array}{l}\text { parcie statyczne i dynamiczne wody przy maksymalnym } \\
\text { poziomie piętrzenia } 2\left(Z_{\mathrm{H} 2}\right) \text {, o ile } Z_{\mathrm{H} 2}>Z_{\mathrm{H} 1} \text { e } \\
\text { static pressure and flow force of water at maximum water } \\
\text { level } 2\left(\mathrm{Z}_{\mathrm{H} 2}\right) \text {, as long as } Z_{\mathrm{H} 2}>Z_{\mathrm{H} 1} \text { e }\end{array}$ & - & - & - & - & - & - & $X$ & - & - \\
\hline & $\begin{array}{l}\text { rzadkie oddziaływania temperaturowe } \\
\text { unusual thermal effects }\end{array}$ & - & - & - & - & - & - & - & $X$ & - \\
\hline & obliczeniowe trzęsienie ziemi ${ }^{\mathrm{g}}$ - design basis earthquake ${ }^{\mathrm{g}}$ & - & - & - & - & - & - & - & - & $\mathrm{X}$ \\
\hline
\end{tabular}

a Warunki budowy oraz stan ,pusty zbiornik”.

Construction and "empty reservoir" condition.

b Przypadek obciążeń tylko do sprawdzenia użytkowalności.

This loading condition only apllies to serviceability verification.

c Można przyjąć parcie statyczne oraz dynamiczne odpowiadające normalnemu poziomowi piętrzenia $Z_{\mathrm{S}}$.

Static pressure and flow force of water related to standard operating water level $Z_{\mathrm{S}}$ can be applied.

${ }^{\mathrm{d}}$ Poziom piętrzenia $Z_{\mathrm{V}}$ równy rzędnej korony przelewu lub górnej krawędzi urządzeń upustowych.

Water level $Z_{v}$ is equal to the elevation of the spillway crest or of the spillway gates' upper edge.

e Poziomy piętrzenia $Z_{\mathrm{H} 1}$ i $Z_{\mathrm{H} 2}$ to maksymalne poziomy piętrzenia występujące w czasie wezbrań o przepływach $\mathrm{BHQ}_{1}$ oraz $\mathrm{BHQ}_{2}(\mathrm{DIN}$ 19700-11:2004-07).

Water levels $\mathrm{Z}_{\mathrm{H} 1}$ and $\mathrm{Z}_{\mathrm{H} 2}$ are maximum water levels associated with flood flows $\mathrm{BHQ}_{1}$ and $\mathrm{BHQ}_{2}$ (DIN 19700-11:2004-07).

f Za eksploatacyjne trzęsienie ziemi uznaje się trzęsienie o prawdopodobieństwie przekroczenia $\mathrm{w}$ ciągu roku wynoszącym 2 x $10^{-3}$ ( $T=500$ lat) dla zapór klasy 1 lub $10^{-2}(T=100$ lat) dla zapór klasy 2.

Operating basis earthquake is an earthquake with yearly exceeding probability of $2 \times 10^{-3}\left(T=500\right.$ years) for class 1 dams or $10^{-2}$ $(T=100$ years) for class 2 dams.

g Za obliczeniowe trzęsienie ziemi uznaje się trzęsienie o prawdopodobieństwie przekroczenia w ciągu roku wynoszącym $4 \mathrm{x} 10^{-4}$ $(T=2500$ lat $)$ dla zapór klasy 1 oraz $10^{-3}(T=1000$ lat $)$ dla zapór klasy 2 .

Design basis earthquake is an earthquake with yearly exceeding probability of $4 \times 10^{-4}\left(T=2500\right.$ years) for class 1 dams or $10^{-3}$ $(T=1000$ years) for class 2 dams.

Przy sprawdzeniu obliczeniowym nośności zapór betonowych lub murowych oraz ich podłoża obowiązują następujące zasady:

Sytuacja obliczeniowa BS I i BS II:

- przy obliczeniach według teorii belek (założenie o płaskich przekrojach poprzecznych) należy wykluczyć wystąpienie pionowych naprężeń rozciągających oraz rozwartych szwów na stronie odwodnej i odpowietrznej przekroju poprzecznego nośnego oraz w połączeniu z gruntem,

- przy obliczeniach opartych na mechanice ośrodka ciągłego (metoda elementów skończonych) z nieliniowym modelem rozkładu temperatury i/lub ciśnienia w szwach i porach można dopuścić pewną ograniczoną rozwartość szczelin - dla murów kamiennych, tam gdzie konieczne, także wbrew ustaleniom DIN 19702; w sytuacji BS I szczeliny te nie mogą sięgać do stref szczelnych lub drenowanych, a w sytuacji BS II nie mogą tych stref przenikać; siła wypadkowa przenoszona przez beton lub mur musi zawsze być przyłożona $\mathrm{W}$ obrębie rdzenia przekroju poprzecznego zapory.

Sytuacja obliczeniowa BS III:

- przy obliczeniach według teorii belek (założenie o płaskich przekrojach poprzecznych) dopuszczalne są rozwartości szwów sięgające w ogólnym przypadku do połowy przekroju poprzecznego przenoszącego obciążenia oraz połączenia $\mathrm{z}$ gruntem, 
Kledyński, Z. i Krysiak, Ł. (2017). Bezpieczeństwo budowli piętrzących - studium porównawcze dokumentów normatywnych. Acta Sci. Pol. Architectura, 16 (3), 89-96. doi: 10.22630/ASPA.2017.16.3.09.

- przy obliczeniach opartych na mechanice ośrodka ciągłego (metoda elementów skończonych) mimośród siły wypadkowej przenoszonej przez beton lub mur może być równy najwyżej jednej trzeciej szerokości przekroju nośnego.

Nie można zapobiec powstaniu pionowych szczelin w podłożu po stronie odwodnej. Należy uwzględnić ten fakt przy modelowaniu parcia wody. Należy wziąć pod uwagę zmiany w przepuszczalności hydraulicznej na skutek powstawania szczelin. W obszarze rozwartych szczelin należy przyjmować stale pełną wartość ciśnienia hydrostatycznego.

W kontekście powyższych uwag miarodajne są następujące obliczenia sprawdzające:

- sprawdzenie nieprzekroczenia dopuszczalnych naprężeń głównych,

- sprawdzenie zarysowanych połączeń (przy uwzględnieniu ciśnienia wody w rysach, z wyjątkiem rys powstających i pogłębiających się w razie trzęsienia ziemi),

- sprawdzenie możliwości przeniesienia sił w szwach budowli, w powierzchni kontaktu zapory z podłożem gruntowym oraz między warstwami różnych gruntów budujących podłoże.

Przy sprawdzeniu nośności należy przestrzegać wartości całkowitych współczynników bezpieczeństwa $(\gamma)$ zestawionych w tabeli 4.

Tabela 4. Całkowite współczynniki bezpieczeństwa dla zapór betonowych i murowych

Table 4. Safety factors for masonry and concrete dams

\begin{tabular}{lcc}
\hline $\begin{array}{l}\text { Sprawdzenie nośności dla } \\
\text { Structural safety verification in terms of }\end{array}$ & $\begin{array}{c}\text { Całkowite współczynniki bezpieczeństwa }(\gamma) \\
\text { w sytuacjach obliczeniowych (BS) } \\
\text { Safety factors }(\gamma) \text { in design situations (BS) }\end{array}$ \\
\cline { 2 - 2 } $\begin{array}{l}\text { Naprężeń głównych w betonie niezbrojonym, murze z kamienia lub bloków } \\
\text { skalnych }\end{array}$ & BS I & BS II \\
Principal stress in non-reinforced concrete, walls made of stone or rock boulders & 2,1 & 1,7 \\
$\begin{array}{l}\text { Poślizgu w posadowieniu lub spoinach budowli } \\
\text { Sliding of foundations or in joints of the structure }\end{array}$ & 1,5 & 1,3 \\
$\begin{array}{l}\text { Poślizgu w uskokach w podłożu skalistym } \\
\text { Sliding of rock layers along joint surfaces in subsoil }\end{array}$ & 2,0 & 1,2 \\
\hline
\end{tabular}

Przenoszenie sił w szwach budowli lub powierzchniach oddzielających może być sprawdzone w ogólnym przypadku z uwzględnieniem udziału oporów tarcia oraz spójności pozornej.

Zdolność podłoża do przeniesienia określonego obciążenia może być uwzględniona, jeżeli związane z nią przemieszczenia budowli są dopuszczalne.

\section{PODSUMOWANIE}

Przedstawione porównanie przepisów polskich i niemieckich dotyczących warunków technicznych budowli piętrzących, ograniczone tylko do sprawdzania stateczności i nośności, wskazuje na różnice, które powinny zachęcić dodatkowo do nowelizacji rozporządzenia (Dz.U. $2007 \mathrm{nr} 86$ poz. 579), wskazanej także z wielu innych powodów. Warto przy tym zauważyć, że norma DIN 19700-11:2004-07 ustanowiona piętnaście lat po formalnym zjednoczeniu państw niemieckich, w których rozwijane były różne systemy normalizacji technicznej, utrzymała dwutorowość sprawdzania nośności, za czym przemawia szereg względów praktycznych i po- 
trzeba zbierania doświadczeń na temat ich równoważenia. Podobne problemy istnieją w polskiej hydrotechnice, gdzie wciąż nie w pełni zaadaptowano metodę stanów granicznych. Procesu tego nie ułatwia pojawianie się nowych dokumentów europejskich: norm EN, w tym eurokodów, gdyż rozwijane są one z różną dynamiką, a w projektowaniu budowli hydrotechnicznych muszą być stosowane w skojarzeniu ze sobą, gdyż składają się na bezpieczeństwo integralnego obiektu. Dlatego odesłanie do polskich norm zawarte w rozporządzeniu (Dz.U. $2007 \mathrm{nr} 86$ poz. 579) nie jest wystarczającym rozwiązaniem.

Pragmatyka wskazuje, aby w potrzebnej nowelizacji rozporządzenia (Dz.U. $2007 \mathrm{nr} 86$ poz. 579) dokonać przynajmniej klarownego rozdziału na obszary, w których stosowanie metody stanów granicznych jest możliwe i potrzebne, i obszary, w których metody klasyczne są wciąż wystarczające lub potrzebne, np. z braku dostatecznego rozpoznania skutków stosowania metod nowocześniejszych.

\title{
PIŚMIENNICTWO
}

DIN 19700-11:2004-07. Stauanlagen. Teil 11: Talsperren.

Rozporządzenie Ministra Ochrony Środowiska, Zasobów Naturalnych i Leśnictwa z dnia 20 grudnia 1996 r. w sprawie warunków technicznych, jakim powinny odpowiadać obiekty budowlane gospodarki wodnej i ich usytuowanie (Dz.U. $1997 \mathrm{nr} 21$ poz. 111).

Rozporządzenie Ministra Środowiska z dnia 20 kwietnia 2007 r. w sprawie warunków technicznych, jakim powinny odpowiadać budowle hydrotechniczne i ich usytuowanie (Dz.U. $2007 \mathrm{nr} 86$ poz. 579).

Świdziński, W. i Korzec, A. (2015). Opracowanie procedury projektowania zapór OUOW Żelazny Most do wyższych rzędnych metoda elementów skończonych oraz uproszczona metoda Newmarka z uwzględnieniem obciązeń parasejsmicznych oraz zaleceń Eurokodu 8. Gdańsk: IBW PAN.

\section{DAM SAFETY - COMPARATIVE STUDY OF NORMATIVE DOCUMENTS}

\begin{abstract}
The current Polish law regulations in the field of design of hydraulic structures are partially incomplete and unclear. The paper discusses these flaws using the example of rules concerning structural safety of dams, where references to invalid standards, unexplained terms and a variety of different design approaches can be found, some of which are significantly outdated relative to the European Standards that are being introduced. For the sake of comparison, some parts of the German Standard DIN 19700-11:2004-07 are quoted, where a structured classification of operating and loading conditions is suggested, as well as a complete list of loads and their combinations for structural analysis. Based on the safety factor approach, the document also describes requirements for all design situations. Additionally, it creates the opportunity to introduce partial safety factor approach dependent on experience of the designers.
\end{abstract}

Key words: hydrotechnical structures, design methods, structural reliability 